\title{
Ionic liquid based PVDF/PMMA gel polymer electrolyte for lithium rechargeable battery
}

\author{
N. F. M. Yusoff and N. H. Idris* \\ School of Ocean Engineering, Universiti Malaysia Terengganu, \\ 21030 Terengganu, Malaysia \\ *Email address: nurulhayati@umt.edu.my \\ Tel: +6096683185, Fax +0696683391
}

\begin{abstract}
The microstructure of a polymer blend as a gel polymer electrolyte affects significantly the electrochemical performances of a Lithium ion battery. Therefore, an appropriate control of the composition of the blending is crucial to obtain a porous structure. In this paper, PVDF/PMMA membrane was successfully prepared via phase-separation method by using salicylic acid as a foaming agent to produce a porous structure within the polymer blend matrix. Ionic liquid-salt mixtures of 1-ethyl-3 methyl imidazolium triflouromethanysulfonyl imide and lithium bis-triflouromethylsulfonyl imide were used to activate the PVDF/PMMA membrane. The as-prepared PVDF/PMMA membrane contains pores when observed from scanning electron microscope, which leads to the high ionic-liquid electrolyte uptake. The membrane with $10 \mathrm{wt} \%$ PVDF and $90 \mathrm{wt} \%$ PMMA exhibited a high ionic conductivity of $3.097 \mathrm{mS} \mathrm{cm}^{-1}$ at room temperature with high lithium ion transference number (0.7922) and wide electrochemical stability window (4.3 V). Its electrochemical performance was evaluated by $\mathrm{LiFePO}_{4}$ half-cell, suggesting that this ionic-liquid gel polymer electrolyte is possible to be developed as an electrolyte in lithium rechargeable battery.
\end{abstract}

Keywords: Polymer blend; foaming agent; ionic liquid; lithium rechargeable battery.

\section{INTRODUCTION}

The lithium-ion battery is an electrical storage device with its high-energy density, low self-discharge, and less in lost memory effect [1]. Regarding the continued growth of the lithium-ion battery, the development of rechargeable battery is one of considerable importance due to the increasing energy consumption in portable devices [2]. As a remarkably efficient, the application of batteries can replace fuel cell and engines to power vehicles, power national supply grids and all sorts of other stationary and mobile applications [3]. However, safety becomes the major issue preventing the widespread commercialization of storage systems [4]. The commercial lithium-ion battery uses the organic liquid electrolyte that is unsafe since the organic solvent is often highly volatile and flammable, which bears the high risk of leakage that, can cause corrosion during packaging although it has very high conductivity $[4,5]$. To overcome this issue, ionic liquid and gel polymer electrolyte has been proposed without scarifying its high ionic conductivity as well as good mechanical strength, [6, 7]. Microporous gel polymer electrolyte has been widely investigated and the porous structure of the membrane is generally created by the phase inversion method [4, 8, 9]. Microporous gel polymer 
electrolyte usually exhibit high ionic conductivity at room temperature $\left(10^{-4}-10^{-3} \mathrm{~S} \mathrm{~cm}^{-1}\right)$ [10] which is close to that of the commercial electrolyte. However, these membranes mostly present poor mechanical property because its physical structure has been softened after uptake of liquid electrolyte. This might cause the problems of winding tension and internal short-circuit during the cell assembly and operation, and indispensible for the practical application [5]. Therefore, the polymer blend is chosen as an alternative to improve the mechanical properties of the polymer matrix while maintaining its pores integrity since the pore structure is the key component to a good thermal stability, large electrochemical window, better ionic conductivity as well as good processability. The most common polymer used as the blended polymer is PVDF because it has high dielectric constant, strongly electron withdrawing functional group (C-F) and good mechanical property [11]. The conductivity of gel polymer electrolyte can be enhanced by using polymer host having a low glass transition temperature, $\mathrm{Tg}$. A variety of PMMAbased gels consisting of solutions of lithium salts in PC-EC mixture also reported by Scrosati et al.[12]. Due to its good optical properties, PMMA becomes a good candidate for non-linear optical applications in communicational technology when blended with semi-crystalline poly vinylidene fluoride (PVDF). Recently, researches are being focused on the development of porous gel polymer electrolytes [13, 14]. Preparing porous PVDF membrane is an available way to obtain gel polymer electrolyte as the pores can accommodate a large amount of liquid electrolyte $[15,16]$. Therefore, more attention has been devoted to increasing the liquid electrolyte content in the polymer matrix by controlling the porous structure by using a physical foaming agent [17]. For gel polymer electrolyte, the polymer membrane was prepared via phase-separation method and activated by immersing it in a liquid electrolyte and leaving it in an anhydrous environment until being gelled $[18,19]$ and then, subjected to further characterizations [20-22]. Almost all the characteristics possessed by ionic liquid well suits for the application of polymer electrolytes. Here, ionic liquids based electrolytes are one alternative that has good chemical and thermal stability, negligible vapor pressure, nonflammability, high ionic conductivity, and a wide electrochemical window with melting temperatures lower than $100{ }^{\circ} \mathrm{C}$ have been intensively studied as alternative electrolytes $[23,24]$. Ionic liquid from the name itself gives an idea of its physical state that presents in liquid form. Apart from this, the presence of ionic liquid in liquid form makes it easier to be miscible with the added constituents without requiring any additional dissolving step [25]. Different types of ionic liquids, such as those with cations based on imidazolium, pyrrolidinium, piperidinium and quaternary ammonium, have been investigated as electrolytes for lithium battery applications [26-29], some of which are used as the solvents when incorporated in gel polymer electrolytes [30].

To improve the physical properties and electrolytes affinity, for the first time, porous polymer membrane of PVDF/PMMA by using salicylic acid as a foaming agent was prepared via the phase-separation method in a mixture of $N$-methyl pyrrolidone (NMP) as a solvent and ionic liquid of EMITFSI mixed with the lithium salt, LiTFSI as an activated the polymer membrane. Based on the foaming idea, the researchers found that urea and the combination of sodium bicarbonate and citric acid can produce porous structure [17, 31] and salicylic acid one of goods in terms of produced pores. Electrochemical measurement of the obtained porous gelled polymer electrolytes shows its promising application in rechargeable lithium batteries. The effects of PMMA at different ratios have been characterized based on their morphology, and electrochemical performance with the aim of obtaining better conductivity gel polymer electrolyte for a lithium-ion rechargeable battery application. 


\section{METHODS AND MATERIALS}

\section{Experimental Procedure}

The PVDF/PMMA membrane was prepared by using the phase-separation method. First, the required amounts of poly (vinylidene flouride) (PVDF) and poly (methyl methacrylate) (PMMA) were dissolved in $N$-methyl pyrrolidone (NMP) and stirred at 80 ${ }^{\circ} \mathrm{C}$ for $4 \mathrm{~h}$. Next, $10 \mathrm{wt} . \%$ of salicylic acid was added to the solution and stirred at room temperature until the transparent and homogenous mixture was formed. Then, the viscous solution was cast into a petri dish and heated at $80{ }^{\circ} \mathrm{C}$ for $48 \mathrm{~h}$ under vacuum. During this process, NMP was evaporated and left a thin PVDF/PMMA membrane. Next, the membrane was heated at $180{ }^{\circ} \mathrm{C}$ for $30 \mathrm{~min}$ and the pores formed from the voids left by salicylic acid. To prepare the gel polymer electrolyte, the membrane was activated in an ionic liquid-salt mixture $\left(0.2 \mathrm{~mol} \mathrm{~kg} \mathrm{~kg}^{-1}\right.$ lithium bis-triflouromethyl sulfonyl imide (LiTFSI) in 1-ethyl-3-methyl imidazolium triflouromethylsulfonyl imide (EMITFSI) [32]. This process was carried out in argon-filled glove box. The composition of the prepared PVDF/PMMA membranes and its corresponding gel polymer electrolytes are listed in Table 1.

Table 1. Composition of PVDF/PMMA membranes and corresponding gel polymer electrolytes.

\begin{tabular}{ccc}
\hline $\begin{array}{c}\text { Composition of PVDF/PMMA } \\
(\text { wt.\%/wt.\%) }\end{array}$ & $\begin{array}{c}\text { Porous } \\
\text { membrane }\end{array}$ & $\begin{array}{c}\text { Gel polymer } \\
\text { electrolyte }\end{array}$ \\
\hline $100 / 0$ & M0 & E0 \\
$90 / 10$ & M10 & E10 \\
$70 / 30$ & M30 & E30 \\
$50 / 50$ & M50 & E50 \\
$30 / 70$ & M70 & E70 \\
$10 / 90$ & M90 & E90 \\
$0 / 100$ & M100 & E100 \\
\hline
\end{tabular}

\section{Characterization of the polymer membranes and polymer electrolytes}

The morphology of the polymer membrane was characterized by scanning electron microscope (SEM, JOEL JSM-6360LA). Attenuated total reflection-Fourier transform infrared (ATR-FTIR) measurement was recorded by Thermo Nicolet 380 FTIR spectrometer from 500 to $4000 \mathrm{~cm}^{-1}$. X-Ray diffraction (XRD) was conducted by using the Rigaku Miniflex II with monochromatic $\mathrm{Cu}-\mathrm{K} \alpha$ radiation $(\lambda=1.5406 \AA)$. The polymer membrane was scanned from 5 to $80^{\circ}$ at a rate of $2^{\circ} \mathrm{min}^{-1}$. The liquid electrolyte uptake of the polymer membrane was measured according to the procedure as follows: the polymer membrane was cut into $1 \mathrm{~cm}^{2}$. Then, the polymer membrane was weighed before immersed in the mixture of ionic liquid-salt for $40 \mathrm{~min}$ and weighed again. The electrolyte uptake was calculated using the following equation:

$$
\text { Electrolyte uptake }(\%)=\frac{w_{t}-w_{0}}{w_{0}} \times 100 \%
$$

where $w_{t}$ and $w_{o}$ are the weights of the wet and dry polymer membranes, respectively. The ac impedance was measured by using a CHI 700E electrochemical workstation instrument in the frequency range of $10 \mathrm{mHz}$ and $100 \mathrm{kHz}$. The gel polymer electrolyte 
was sandwiched between the two blocking stainless steel electrodes. The ionic conductivity $(\sigma)$ of the gel polymer electrolyte was calculated based on the following equation:

$$
\sigma=\frac{t}{R_{b} A}
$$

where, $R_{\mathrm{b}}(\Omega)$ is the bulk resistance, $t(\mathrm{~cm})$ is the thickness of the gel polymer electrolyte and $\mathrm{A}\left(\mathrm{cm}^{2}\right)$ is the area of the surface contact. The impedance measurement was also carried out at different temperature ranging from 303 to $363 \mathrm{~K}$. Lithium-ions transference number $\left(T_{L i}^{+}\right)$was calculated by conducting a chronoamperometry measurement of $\mathrm{Li} / \mathrm{gel}$ polymer electrolyte/Li cell at a constant polarization potential of $10 \mathrm{mV}$. Ac impedance of the cell was also measured before and after chronoamperometry measurement. This analysis was performed by using Autolab PGSTAT 302 (Eco-chemie). The $T_{L i}^{+}$can be calculated by using the following equation:

$$
T_{L i}^{+}=\frac{I_{S S}\left(\Delta V-I_{0} R_{i 0}\right)}{I_{0}\left(\Delta V-I_{S S} R_{i}\right)}
$$

In this equation, the subscripts of 0 and $s s$ are indicated as initial current value and steadystate polarization current, respectively. $I$ is the current value and $\Delta V$ is the applied potential difference. The measurements of $R_{i o}$ and $R_{i}$ are electrode resistance of the cell before and after dc polarization. The electrochemical stability window of the gel polymer electrolyte was determined by linear sweep voltammetry (LSV) using a stainless steel working electrode and lithium foil as the counter electrode at the scanning rate of 1 $\mathrm{mV} \mathrm{s}^{-1}$.

\section{Electrochemical Characterization}

The electrode was prepared by dissolving $75 \mathrm{wt} . \%$ of $\mathrm{LiFePO}_{4}, 20 \mathrm{wt} . \%$ carbon black and 5 wt.\% PVDF in NMP. The slurry was pasted onto aluminium foil and dried at $100^{\circ} \mathrm{C}$ under vacuum. Here, gel polymer electrolyte with the highest conductivity was chosen for electrochemical testing. The $\mathrm{Li} / \mathrm{E} 90 / \mathrm{LiFePO}_{4}$ cell was fabricated in an argon-filled glove box. The charge and discharge testing were performed galvanostatically between 2.5 and $4.2 \mathrm{~V}$ at room temperature on a Neware battery tester.

\section{RESULTS AND DISCUSSION}

The liquid electrolyte uptake for the gel polymer electrolytes was calculated according to Eq. (1). Figure 1 shows E0 reach the saturation with the electrolyte uptake at $35 \%$. With the addition of 10wt. \% of PMMA to the polymer matrix, sample E90 reaches saturation with a maximum liquid electrolyte uptake ratio of $122.2 \%$. Therefore, the addition of PMMA does not only give the control the porosity but also resulting in the high of ionic conductivity of the membrane. The surface morphology of PVDF/PMMA has been carried out by SEM and the images are shown in Figure 2. From the Figure 2(a), the pure PMMA membrane has a compact and flat surface. By decreasing the PMMA amount, the effect on crystallization of PVDF become complex. As the weight ratio of PVDF /PMMA less than 90 wt.\% of PMMA, these membranes (Figure 2(b-g)) show a network structure 
and pores are identified and well connected. These results are in agreement with the SEM images.

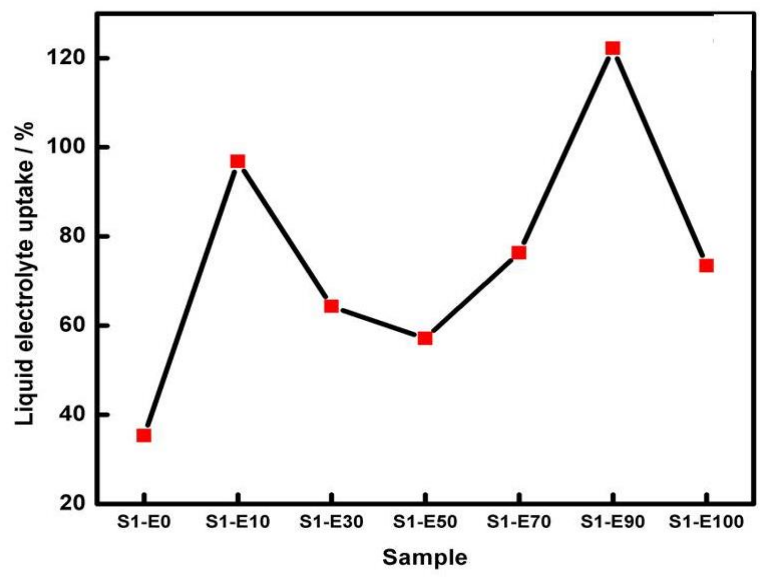

Figure 1. Liquid electrolyte uptake for sample M0-M100.
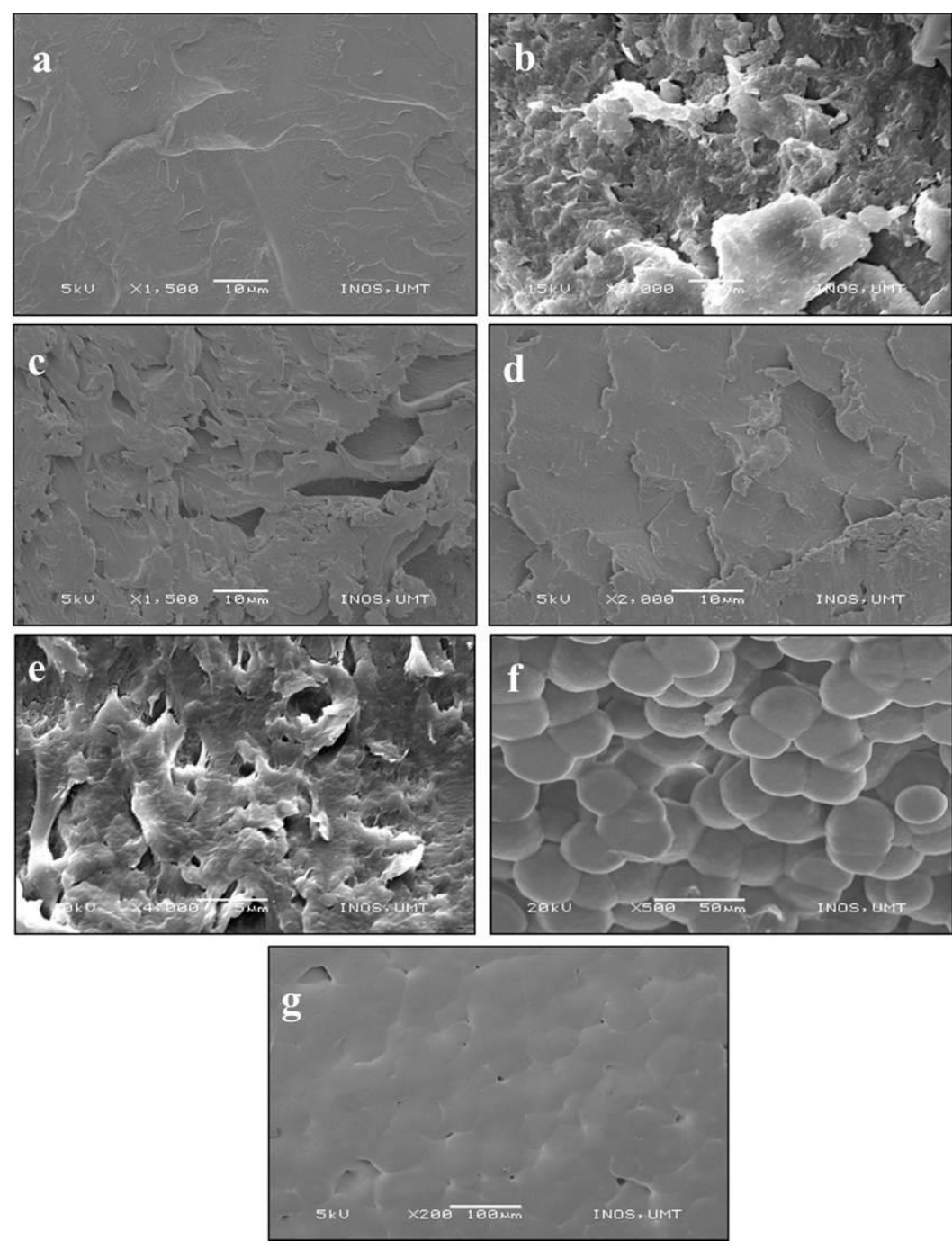

Figure 2. Cross-sectional of SEM images for samples; (a) M0, (b) M10, (c) M30, (d) M50, (e) M70, (f) M90, and (g) M100. 


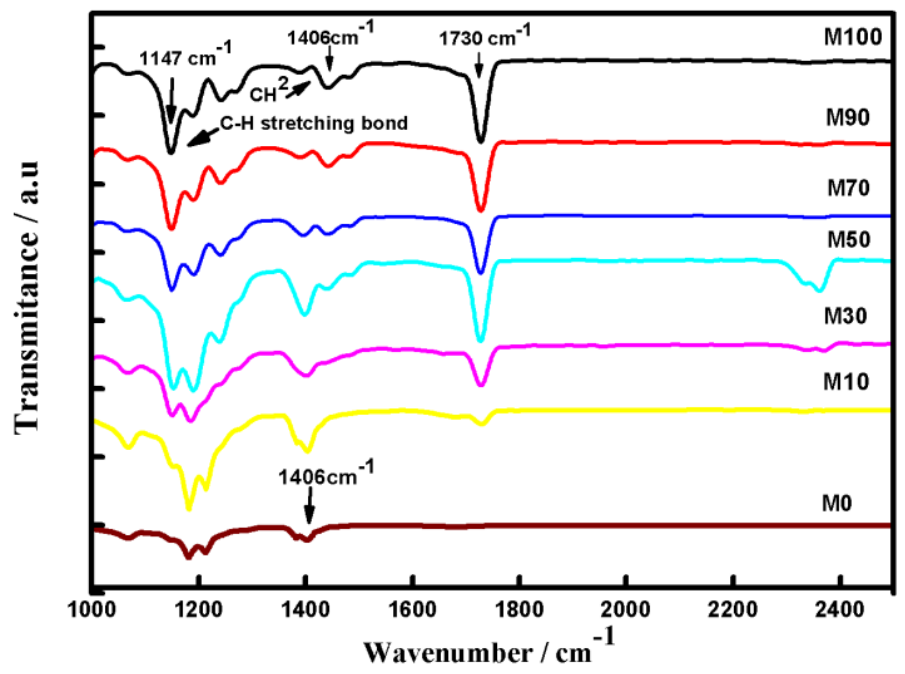

Figure 1. ATR-FTIR spectra of the samples M0, M10, M30, M50, M70, M90, and M100.

ATR-FTIR spectra of the membranes are shown in Figure 3. For sample M100, the vibrational peaks at $1406 \mathrm{~cm}^{-1}$ corresponding to $\mathrm{CH}_{2}$ wagging deformation. With the addition of PVDF, the intensity of this peak became weak and less intense. The absorption peaks at $1387 \mathrm{~cm}^{-1}$ are assigned to the $\mathrm{CH}_{2}$ twisting modes of PMMA. The peaks at 1200 $\mathrm{cm}^{-1}$ and $1152 \mathrm{~cm}^{-1}$ are assigned to the stretching frequency of $\mathrm{C}-\mathrm{F}$ and $\mathrm{CF}_{2}$ respectively. For sample M0, it shows that reflecting peak at $1730 \mathrm{~cm}^{-1}$ representing the stretching of the carbonyl group $(\mathrm{C}=\mathrm{O})$. However, this peak gradually decreased with the decreased of the concentration of PVDF. Therefore, these results confirmed the specific interaction between the carbonyl groups of PMMA and the $\mathrm{CH}_{2}$ groups of PVDF [33]. The crystallinity of the polymer membranes was characterized by the XRD as shown in Figure 4. Clearly, PVDF is partially crystalline in nature. With the addition of PMMA, the intensities of these diffraction peaks decrease progressively, and tend to become amorphous in the blended membrane. Therefore, the crystallinity of the membranes decreased with the increased PMMA concentration.

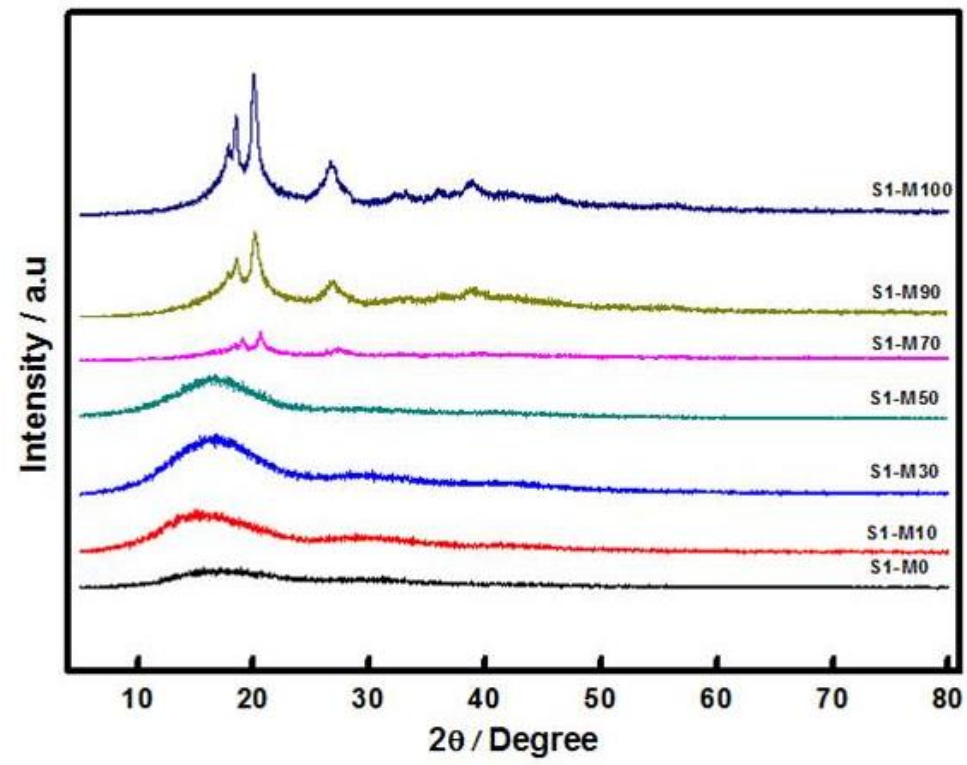

Figure 2. The XRD pattern of samples M0, M10, M30, M50, M70, M90, and M100. 

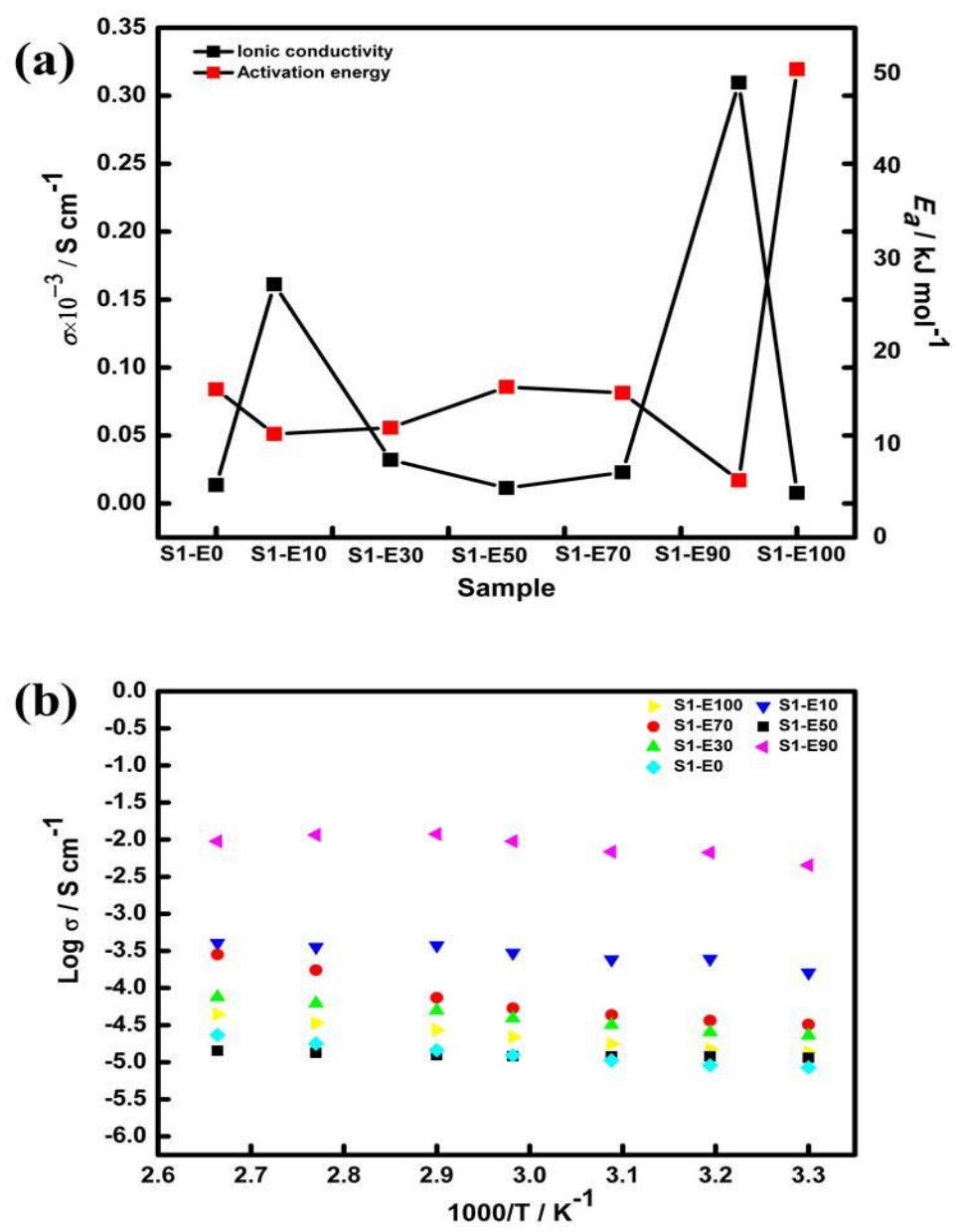

Figure 3. (a) Ionic conductivity and activation energy, and (b) Arrhenius plots of gel polymer electrolyte (E0-E100).

The ionic conductivity of PVDF/PMMA gel polymer electrolytes at room temperature are shown in Figure 5(a). When the polymer membrane soaked in the ionic liquid-salt mixture, the membrane was gelled by the solvent to form gel polymer electrolyte. The ionic conductivity of the gel polymer electrolyte is $3.097 \times 10^{-3} \mathrm{~S} \mathrm{~cm}^{-1}$ for sample E90. The possible of transferred carrier ions within the porous polymer electrolyte based on the possible ways: (1) the trapped of liquid electrolyte in pores membrane, (2) the swelled of liquid electrolyte through an amorphous domain, and (3) molecular chains along the polymer [34]. The temperature dependent of the ionic conductivities for the gel polymer electrolytes are shown in Figure 5(b). The typical behavior of the polymer electrolytes shows that the ionic conductivity increased with the increasing of the temperature. High temperature not only results in the anion of the polymer but also promotes the migration of carrier ions [35]. This expansion produces local empty space and increases the free volume in terms of promotes the motion of polymer segments and carrier ions [36]. From the gradient of the Arrhenius plot, the activation energy $\left(E_{\mathrm{a}}\right)$ of the polymer electrolytes were calculated (Figure 5(a)) which is the energy of the defect formation combined with the energy required for ions to migrate. The $E_{\mathrm{a}}$ was calculated according to the Eq. (4) as: 


$$
\sigma=\sigma_{0} \exp \left(-E_{a} / R T\right)
$$

where $\sigma$ is the conductivity of the gel polymer electrolyte, $\sigma_{0}$ is a pre-exponential factor, $E_{\mathrm{a}}$ is the activation energy, $R$ is the gas constant, and $T$ is the temperature. These porous polymer membranes absorb large amounts of electrolyte forming the gelled polymer electrolytes whose ions migrate easily through the absorbed electrolyte. Consequently, with increasing of the electrolyte uptake, the activation energy for ions transportation decreases and the ionic conductivity of the resulting polymer electrolyte increases. Therefore, the migration of lithium ions is much easier with more tunnels in the polymer membranes [37].

In the PVDF/PMMA gel polymer electrolyte, the mixture ionic liquid-salt plays a crucial role in order to improve the ionic conductivity of polymer electrolyte at a room temperature. Therefore, the gel polymer electrolyte film should have higher Li-ion transference number. According to the Bruce and Vincent method, we carried out AC measurements and chronoamperometry to calculate the Li-ion transference number $\left(T_{L i}^{+}\right)$. The $T_{L i}^{+}$was calculated according the Eq. (3). Figure 6 shows the typical curves of the chronoamperometry profile of samples E0 - E100 at room temperature. The data of ac measurements before and after chronoamperometry and its corresponding of $T_{L i}^{+}$are tabulated in Table 2 .

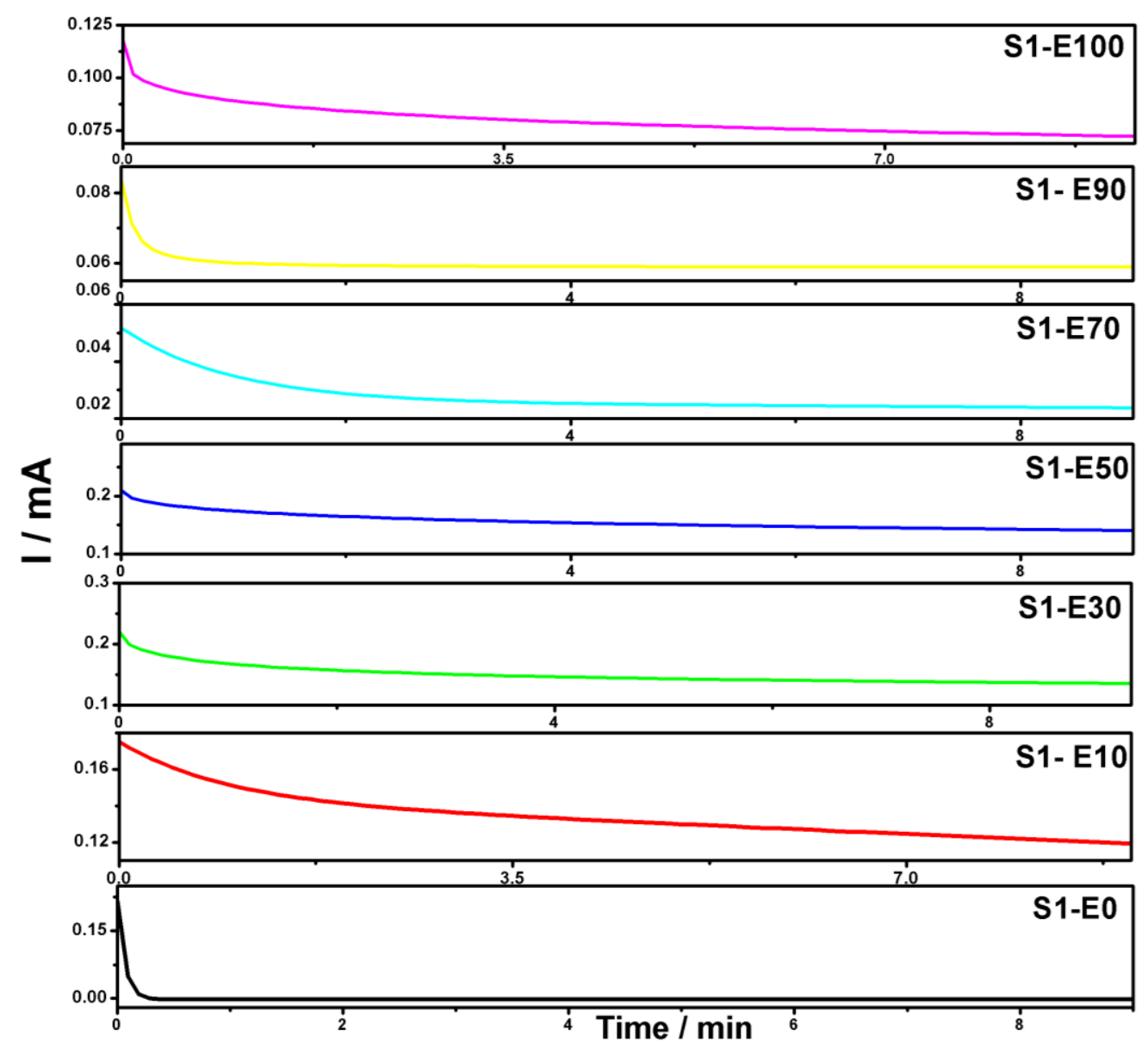

Figure 4. Chronoamperometry curves of samples E0, E10, E30, E50, E70, E90, and E100. 
Table 2. Lithium-ion transference number $\left(T_{L i}^{+}\right)$and resistance of the gel polymer electrolyte before and after dc polarization.

\begin{tabular}{cccc}
\hline Film & $\begin{array}{c}\text { Resistance before dc } \\
\text { polarization } \\
\mathrm{R}_{i 0}(\Omega)\end{array}$ & $\begin{array}{c}\text { Resistance after dc } \\
\text { polarization } \\
\mathrm{R}_{i}(\Omega)\end{array}$ & $\begin{array}{c}\text { Lithium-ions } \\
\text { transference number, }\end{array}$ \\
\hline E0 & $0.520 \times 10^{0}$ & $8.797 \times 10^{0}$ & $T_{L i}^{+}$ \\
E10 & $6.923 \times 10^{0}$ & $2.018 \times 10^{1}$ & 0.5472 \\
E30 & $1.552 \times 10^{2}$ & $3.551 \times 10^{2}$ & 0.5957 \\
E50 & $4.464 \times 10^{2}$ & $5.269 \times 10^{2}$ & 0.5513 \\
E70 & $3.670 \times 10^{3}$ & $2.047 \times 10^{4}$ & 0.5297 \\
E90 & $1.137 \times 10^{3}$ & $1.872 \times 10^{3}$ & 0.5504 \\
E100 & $2.171 \times 10^{3}$ & $2.563 \times 10^{3}$ & 0.7922 \\
\hline
\end{tabular}

It is clearly seen that the sample of E90 has the higher of number in $T_{L i}^{+}$and it is more suitable for lithium battery fabrication. Sample of E90 was chosen as an electrolyte and sandwiched between $\mathrm{LiFePO}_{4}$ as a cathode and lithium metal as an anode to fabricate a coin cell type and subjected to cyclability testing. Correspond to the $0.05 \mathrm{C}$, the current density is $8.5 \mathrm{~mA} \mathrm{~g}^{-1}$ and the voltage range is between 2.5 and $4.2 \mathrm{~V}$. The theoretical specific capacity of $\mathrm{LiFePO}_{4}$ is $170 \mathrm{mAh} \mathrm{g}^{-1}$. For the specific capacity versus cycle number and the columbic efficiency of the cell were shown in Figure 7(a). The discharge capacity at the first cycle is only about $62 \mathrm{mAh} \mathrm{g}^{1}$ and the cell yielded $95 \%$ columbic efficiency. The cycling performance of the $\mathrm{Li} / \mathrm{E} 90 / \mathrm{LiFePO}_{4}$ does not give the best specific capacity and this phenomenon is probably related with the side reaction of the PVDF/PMMA and the mixture of EMITFSI/LiTFSI but still need to figure out this problem in the future works. This problem also related with the pores structure of the membrane and their crystallinity of the sample.

For the charge-discharge profile of the cell, Figure 7(b) shows the 1st, 2nd, 5th, 20th, and 50th cycles. All charge - discharge curve exhibits a flat plateau at $3.4 \mathrm{~V}$ and 3.5 $\mathrm{V}$, which is a typical characteristic of $\mathrm{LiFePO}_{4}$. Linear sweep polarization was conducted to measure the voltage breakdown and investigate the electrochemical stability window sample of E90 gel polymer electrolyte. Commercial electrolyte composed of $1 \mathrm{M} \mathrm{LiPF}_{6}$ in EC/DMC (1:1 by volume) was tested for comparison purpose. It was clearly seen that the polymer electrolyte was stable up to $4.3 \mathrm{~V}$ (Figure 7(c)), which meet the requirement for a practical lithium ion battery. So, based on the other reported of gel polymer electrolyte the potential of electrochemical oxidation is mainly due to the absorbed of liquid electrolyte [22, 37-39]. The above results indicate that salicylic acid is influenced by pore inducer PVDF/PMMA gel polymer electrolyte. From the, SEM analyses all samples show that there is good miscibility between PMMA and PVDF, which indicates that PMMA molecules can be dispersed relatively evenly in the miscible phase and domain interfaces between each phase are indistinct [40]. There is a large difference in morphology and it shows a homogenous surface morphology between the blend. It can be seen clearly from the micrograph (Figure 1) that the PMMA are distributed uniformly in the polymer host [41]. Based on FTIR and XRD analysis, the miscibility in a polymer blend including semi-crystalline component is generally due to the interaction between amorphous parts of each component [40]. In the case PVDF XRD analysis, it is a semi crystalline polymer and there two peaks at about $20^{\circ}$ and $26^{\circ}$ corresponding to its crystalline. For the PMMA it is an amorphous polymer and there are only two wide and weak peaks at $15^{\circ}$ and $30^{\circ}$. 

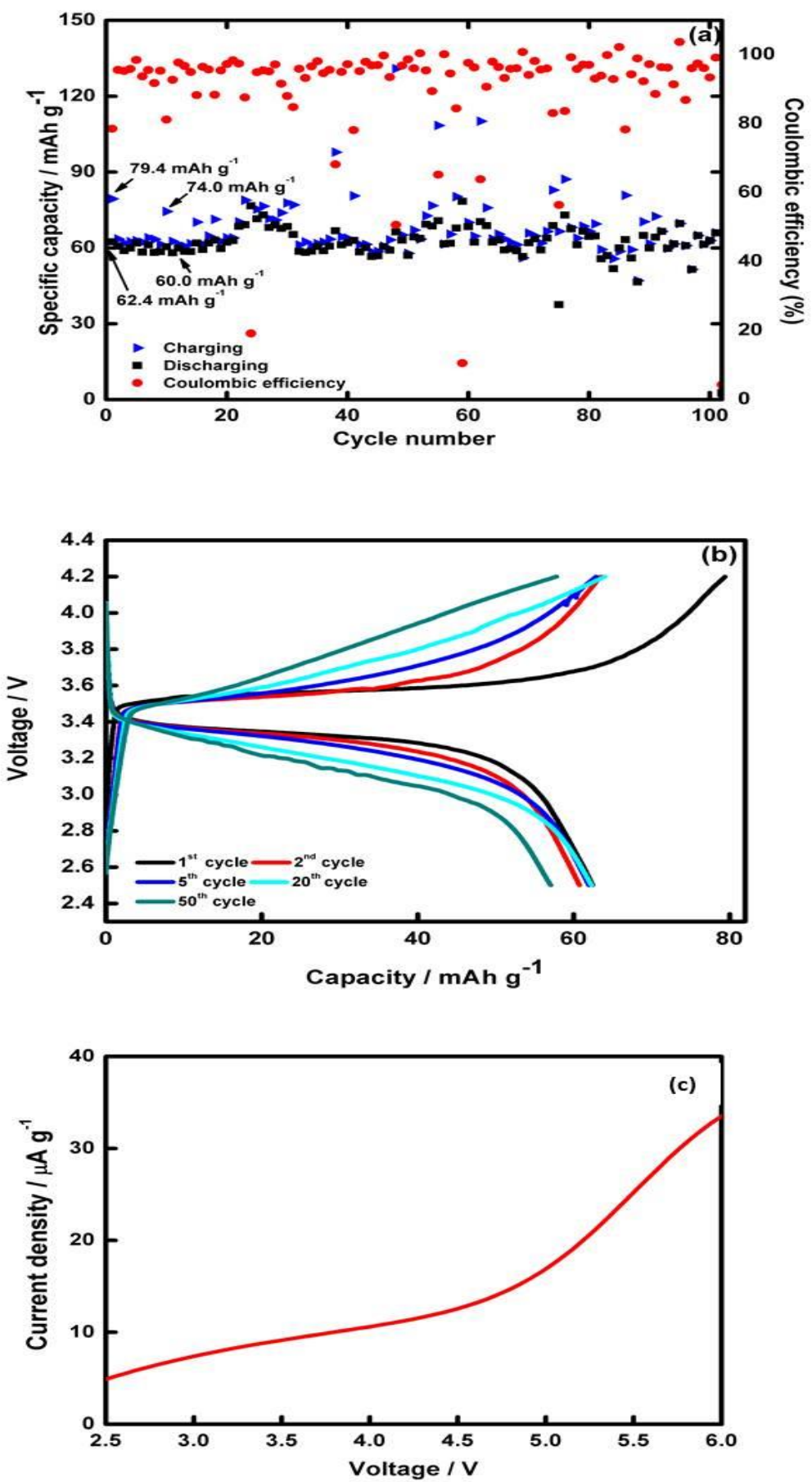

Figure 5. Electrochemical performance of $\mathrm{Li} / \mathrm{E} 90 / \mathrm{LiFePO}_{4}$ cells; (a) cyclic performance and columbic efficiency (corresponding to a $0.05 \mathrm{C}$ ), (b) charge discharge profiles for selected cycles and, (c) linear sweep voltammetry of sample E90 at a scan rate of $1 \mathrm{mV} \mathrm{s}^{-1}$.

However, for the blends polymer the decreased of PVDF becomes more amorphous and the corresponding of the blend membranes can be clearly found [42]. As the PVDF content lower than $70 \mathrm{wt} . \%$, these diffraction peaks were disappeared, indicating that these samples tend to become amorphous. Therefore, the crystallization nature of the PVDF is strongly affected by the addition of PMMA. So that, as in 
PVDF/PMMA blends, the crystallites reduces the limit extensibility of some PVDF segments in the amorphous phase [43]. The FTIR spectra (Figure 3) suggest that the crystallization phases of PVDF in the blend remain to be controlled by the composition of the polymer blend and the common characteristic $\mathrm{C}=\mathrm{O}$ band at $1730 \mathrm{~cm}^{-1}$ [44]. Likewise to the $(\mathrm{C}=\mathrm{O})$ peak, with an increase weight percent of PMMA, the wavenumber is decreased to shorter wavenumber. The ionic conductivity depends on several factors, such as ionic conducting species concentration, cationic or anionic types charge carriers, the charge carrier's mobility and the temperature [45]. Although the performance of the ionic conductivity by using a mixture of EMITFI/LiTFSI is better than commercial electrolytes for lithium ion batteries [46]. The higher of PVDF in the blend leads to the higher of viscosity which in turn lowers the mobility carriers and hence the lower conductivity and it also funds that the increasing of the PMMA it was decreased the conductivity. The decreasing value of $E_{\mathrm{a}}$ for polymer electrolytes with increments ionic conductivity implying that the ions in highly conducting samples require lower energy for migration [47] and it was supported based on the Li-ion transference number. Then, for the higher of ionic conductivity (E90) it used to continue in the battery characterization. The linear sweep voltammetry plot of PEs is shown in Figure 7(c) is found that the current through the sandwiched polymer electrolyte is very small when the cell voltage is lower than $4.5 \mathrm{~V}\left(\mathrm{vs} \cdot \mathrm{Li} / \mathrm{Li}^{+}\right)$, indicating that no decomposition of the components of polymer electrolyte occurs. The results suggest that the as-prepared polymer electrolytes are very suitable for applications in lithium ion battery [42]. The lower resistance of the cell using the PMMA blend polymer electrolyte reduced the capacity decline [48].

\section{CONCLUSIONS}

The highly porous of blend polymer membranes, PVDF/PMMA was successfully prepared by a simple process via phase separation method by using salicylic acid as the foaming agent and immersion of membrane to form the polymer electrolyte in the ionic liquid to activate the membrane. The complexations of the polymer membrane were confirmed by the ATR-FTIR. The degree crystallinity of polymer blends decreased when the addition of the PMMA to PVDF membrane based on the XRD analysis. But by removing salicylic acid does not give the better microporous membrane. SEM that only sample of M90 gives clearer and better pores if compare with the other membranes and it also gives the highest ionic conductivity at room temperature at $3.097 \times 10^{-3} \mathrm{~S} \mathrm{~cm}^{-1}$ and this sample has the lowest activation energy. But, at the same time it improved the lithium -ion transference number, 0.7922. The $\mathrm{Li} / \mathrm{E} 90 / \mathrm{LiFePO}_{4}$ cell showed the unstable electrochemical performance. But the electrochemical stability window was extended up to $4.3 \mathrm{~V}$. Based on all this research, it showed that the PVDF/PMMA blends have the potential for use as an electrolyte in lithium rechargeable batteries since this method is simple and convenient to prepare the electrolyte in bulk for the industrial.

\section{ACKNOWLEDGEMENTS}

Financial support provided by the Ministry of Education Malaysia through a Research Acculturation Grant Scheme (RAGS) (Vote no. 57086) is gratefully acknowledged. The authors are grateful to the Ministry of Education Malaysia for MYBRAINs 15 Scholarship. 


\section{REFERENCES}

[1] Lee Y-Y, Liu Y-L. Crosslinked electrospun poly(vinylidene difluoride) fiber mat as a matrix of gel polymer electrolyte for fast-charging lithium-ion battery. Electrochimica Acta. 2017;258:1329-35.

[2] Barchasz C, Leprêtre J-C, Patoux S, Alloin F. Electrochemical properties of etherbased electrolytes for lithium/sulfur rechargeable batteries. Electrochimica Acta. 2013;89:737-43.

[3] Mohamed W, Atan R. Analysis of excessive heating on the thermal and electrical resistance of a polymer electrolyte membrane fuel cell. International Journal of Automotive and Mechanical Engineering. 2012;5:648-59.

[4] Yang P, Liu L, Li L, Hou J, Xu Y, Ren X, et al. Gel polymer electrolyte based on polyvinylidenefluoride-co-hexafluoropropylene and ionic liquid for lithium ion battery. Electrochimica Acta. 2014;115:454-60.

[5] Lu Q, Yang J, Lu W, Wang J, Nuli Y. Advanced semi-interpenetrating polymer network gel electrolyte for rechargeable lithium batteries. Electrochimica Acta. 2015;152:489-95.

[6] Yu B, Zhou F, Wang C, Liu W. A novel gel polymer electrolyte based on poly ionic liquid 1-ethyl 3-(2-methacryloyloxy ethyl) imidazolium iodide. European polymer journal. 2007;43:2699-707.

[7] Xu JJ, Ye H. Polymer gel electrolytes based on oligomeric polyether/cross-linked PMMA blends prepared via in situ polymerization. Electrochemistry Communications. 2005;7:829-35.

[8] Zhang SS, Ervin MH, Xu K, Jow TR. Microporous poly(acrylonitrile-methyl methacrylate) membrane as a separator of rechargeable lithium battery. Electrochimica Acta. 2004;49:3339-45.

[9] Shi Q, Yu M, Zhou X, Yan Y, Wan C. Structure and performance of porous polymer electrolytes based on P(VDF-HFP) for lithium ion batteries. Journal of Power Sources. 2002;103:286-92.

[10] Zhai W, Zhu H-J, Wang L, Liu X-M, Yang H. Study of PVDF-HFP/PMMA blended micro-porous gel polymer electrolyte incorporating ionic liquid [BMIM] $\mathrm{BF}_{4}$ for Lithium ion batteries. Electrochimica Acta. 2014;133:623-30.

[11] Liu J, Li W, Zuo X, Liu S, Li Z. Polyethylene-supported polyvinylidene fluoridecellulose acetate butyrate blended polymer electrolyte for lithium ion battery. Journal of Power Sources. 2013;226:101-6.

[12] Scrosati B, Selvaggi A, Croce F, Gang W. The $\mathrm{Li} / \mathrm{LiV}_{3} \mathrm{O}_{8}$ polymer electrolyte lithium battery III. Investigation of the electrode interfaces. Journal of Power Sources. 1988;24:287-94.

[13] Boudin F, Andrieu X, Jehoulet C, Olsen II. Microporous PVdF gel for lithium-ion batteries. Journal of Power Sources. 1999 81-82 804-7.

[14] Wang H, Huang H, Wunder SL. Novel Microporous Poly(vinylidene fluoride) Blend Electrolytes for Lithium-Ion Batteries. Journal of the Electrochemical Society. 2000;147:2853-61.

[15] Zhao Y-H, Zhu B-K, Kong L, Xu Y-Y. Improving Hydrophilicity and Protein Resistance of Poly(vinylidene fluoride) Membranes by Blending with Amphiphilic Hyperbranched-Star Polymer. Langmuir. 2007;23:5779-86.

[16] Morehouse JA, Lloyd DR, Freeman BD, Lawler DF, Liechti KM, Becker EB. Modeling the stretching of microporous membranes. Journal of Membrane Science. 2006;283:430-9. 
[17] Li ZH, Cheng C, Zhan XY, Wu YP, Zhou XD. A foaming process to prepare porous polymer membrane for lithium ion batteries. Electrochimica Acta. 2009;54:4403-7.

[18] Subramania A, Kalyana Sundaram NT, Sathiya Priya AR, Vijaya Kumar G. Preparation of a novel composite micro-porous polymer electrolyte membrane for high performance Li-ion battery. Journal of Membrane Science. 2007;294:8-15.

[19] Zhang S, Ervin M, Xu K, Jow T. Li-ion battery with poly (acrylonitrile-methyl methacrylate)-based microporous gel electrolyte. Solid State Ionics. 2005;176:416.

[20] Magistris A, Mustarelli P, Quartarone E. Poly(vinylidenefluoride)-based porous polymer electrolytes. Electrochimica Acta. 2001;46:1635-9.

[21] Michot T, Nishimoto A, Watanabe M. Electrochemical properties of polymer gel electrolytes based on poly(vinylidene fluoride) copolymer and homopolymer. Electrochimica Acta. 2000;45:1347-60.

[22] Tarascon JM, Gozdz AS, Schmutz C, Shokoohi F, Warren PC. Performance of Bellcore's plastic rechargeable Li-ion batteries. Solid State Ionics. 1996;86-88, Part 1:49-54.

[23] Lu J, Yan F, Texter J. Advanced applications of ionic liquids in polymer science. Progress in Polymer Science. 2009;34:431-48.

[24] Hofmann A, Schulz M, Hanemann T. Gel electrolytes based on ionic liquids for advanced lithium polymer batteries. Electrochimica Acta. 2013;89:823-31.

[25] Ramesh S, Uma O, Shanti R, Yi LJ, Ramesh K. Preparation and characterization of poly (ethyl methacrylate) based polymer electrolytes doped with 1-butyl-3methylimidazolium trifluoromethanesulfonate. Measurement. 2014;48:263-73.

[26] Appetecchi GB, Montanino M, Carewska M, Moreno M, Alessandrini F, Passerini S. Chemical-physical properties of bis(perfluoroalkylsulfonyl)imide-based ionic liquids. Electrochimica Acta. 2011;56:1300-7.

[27] Jin Y, Zhang J, Song J, Zhang Z, Fang S, Yang L, et al. Functionalized ionic liquids based on quaternary ammonium cations with two ether groups as new electrolytes for $\mathrm{Li} / \mathrm{LiFePO} 4$ secondary battery. Journal of Power Sources. 2014;254:137-47.

[28] Raghavan P, Manuel J, Zhao X, Kim D-S, Ahn J-H, Nah C. Preparation and electrochemical characterization of gel polymer electrolyte based on electrospun polyacrylonitrile nonwoven membranes for lithium batteries. Journal of Power Sources. 2011;196:6742-9.

[29] Rao M, Geng X, Liao Y, Hu S, Li W. Preparation and performance of gel polymer electrolyte based on electrospun polymer membrane and ionic liquid for lithium ion battery. Journal of Membrane Science. 2012;399-400:37-42.

[30] Cheruvally G, Kim J-K, Choi J-W, Ahn J-H, Shin Y-J, Manuel J, et al. Electrospun polymer membrane activated with room temperature ionic liquid: Novel polymer electrolytes for lithium batteries. Journal of Power Sources. 2007;172:863-9.

[31] Zhang P, Li GC, Zhang HP, Yang LC, Wu YP. Preparation of porous polymer electrolyte by a microwave assisted effervescent disintegrable reaction. Electrochemistry Communications. 2009;11:161-4.

[32] An Y, Zuo P, Cheng X, Liao L, Yin G. Preparation and properties of ionic-liquid mixed solutions as a safety electrolyte for lithium ion batteries. International Journal of Electrochemical Science. 2011;6:2398-410. 
[33] Idris NH, Rahman MM, Wang J-Z, Liu H-K. Microporous gel polymer electrolytes for lithium rechargeable battery application. Journal of Power Sources. 2012;201:294-300.

[34] Saito Y, Kataoka H, Quartarone E, Mustarelli P. Carrier migration mechanism of physically cross-linked polymer gel electrolytes based on PVDF membranes. The Journal of Physical Chemistry B. 2002;106:7200-4.

[35] Cui ZY, Xu YY, Zhu LP, Wang JY, Xi ZY, Zhu BK. Preparation of PVDF/PEOPPO-PEO blend microporous membranes for lithium ion batteries via thermally induced phase separation process. Journal of Membrane Science. 2008;325:95763.

[36] Taib NU, Idris NH. Plastic crystal-solid biopolymer electrolytes for rechargeable lithium batteries. Journal of Membrane Science. 2014;468:149-54.

[37] Li Z, Su G, Gao D, Wang X, Li X. Effect of $\mathrm{Al}_{2} \mathrm{O}_{3}$ nanoparticles on the electrochemical characteristics of $\mathrm{P}(\mathrm{VDF}-\mathrm{HFP})$-based polymer electrolyte. Electrochimica Acta. 2004;49:4633-9.

[38] Torimoto T, Tsuda T, Okazaki K, Kuwabata S. New frontiers in materials science opened by ionic liquids. Adv Mater. 2010;22:1196-221.

[39] Zhang P, Zhang HP, Li GC, Li ZH, Wu YP. A novel process to prepare porous membranes comprising $\mathrm{SnO}_{2}$ nanoparticles and $\mathrm{P}(\mathrm{MMA}-\mathrm{AN})$ as polymer electrolyte. Electrochemistry Communications. 2008;10:1052-5.

[40] Ma W, Zhang J, Wang X, Wang S. Effect of PMMA on crystallization behavior and hydrophilicity of poly(vinylidene fluoride)/poly(methyl methacrylate) blend prepared in semi-dilute solutions. Applied Surface Science. 2007;253:8377-88.

[41] Zhang P, Yang LC, Li LL, Ding ML, Wu YP, Holze R. Enhanced electrochemical and mechanical properties of P(VDF-HFP)-based composite polymer electrolytes with SiO2 nanowires. Journal of Membrane Science. 2011;379:80-5.

[42] Xiao Q, Li Z, Gao D, Zhang H. A novel sandwiched membrane as polymer electrolyte for application in lithium-ion battery. Journal of Membrane Science. 2009;326:260-4.

[43] Jarray J, Larbi FBC, Vanhulle F, Dubault A, Halary JL. Thermal and mechanical behavior of amorphous and semi-crystalline poly(vinylidene fluoride)/poly(methyl methacrylate) blends. Macromolecular Symposia. 2003;198:103-16.

[44] Dirlikov S, Koenig JL. Infrared Spectra of Poly(Methyl Methacrylate) Labeled With Oxygen-18. Applied Spectroscopy. 1979;33:551-5.

[45] Schantz S, Torell LM. Evidence of dissolved ions and ion pairs in dilute poly (propylene oxide)-salt solutions. Solid State Ionics. 1993;60:47-53.

[46] An Y, Cheng X, Zuo P, Liao L, Yin G. The effects of functional ionic liquid on properties of solid polymer electrolyte. Materials Chemistry and Physics. 2011;128:250-5.

[47] Samsudin AS, Khairul WM, Isa MIN. Characterization on the potential of carboxy methylcellulose for application as proton conducting biopolymer electrolytes. Journal of Non-Crystalline Solids. 2012;358:1104-12.

[48] Ma T, Cui Z, Wu Y, Qin S, Wang H, Yan F, et al. Preparation of PVDF based blend microporous membranes for lithium ion batteries by thermally induced phase separation: I. Effect of PMMA on the membrane formation process and the properties. Journal of Membrane Science. 2013;444:213-22. 